Teófico, KMA, Lima, FLS \& Menezes, DB. (2020). Differential and integral calculus: from the fedathi sequence to adavanced mathematical thinking. Research, Society and Development, 9(7):1-19, e435973869.

\title{
Cálculo diferencial e integral: da sequência fedathi ao pensamento matemático
}

$$
\text { avançado }
$$

Differential and integral calculus: from the fedathi sequence to adavanced mathematical thinking

Cálculo diferencial e integral: de la secuencia de fedathi al pensamiento matemático avanzado

Recebido: 22/04/2020 | Revisado: 30/04/2020 | Aceito: 12/05/2020 | Publicado: 21/05/2020

Karllinson Magno Ávila Teófilo

ORCID: https://orcid.org/0000-0002-2240-9881

Universidade Estadual Vale do Acaraú, Brasil

E-mail: karllinson2015@gmail.com

Francisco Leonardo da Silva Lima

ORCID: https://orcid.org/0000-0003-4467-7219

Universidade Estadual Vale do Acaraú, Brasil

E-mail: leonardouvamatematica@gmail.com

Daniel Brandão Menezes

ORCID: https://orcid.org/0000-0002-5930-7969

Universidade Estadual Vale do Acaraú, Brasil

E-mail: brandaomenezes@ hotmail.com

\section{Resumo}

O objetivo deste artigo é apresentar uma pesquisa voltada para o ensino de Cálculo, motivada pelas dificuldades mostradas pelos estudantes especialmente nos conteúdos de Derivadas e Integrais. Busca-se, portanto, entender se a utilização da metodologia de ensino Sequência Fedathi (SF) por parte dos docentes pode desenvolver aspectos do Pensamento Matemático Avançado (PMA) na construção de raciocínio por parte dos discentes. A metodologia se deu com uma inicial revisão de literatura seguido de um estudo de caso tendo como sujeitos os alunos de um grupo de estudos da Universidade Estadual Vale do Acaraú e para análise dos resultados foram observadas as categorias da Teoria Cognitiva PMA elencadas no desenvolvimento da pesquisa. Os resultados apresentaram que a mudança de postura docente 
suscitou outras demandas discentes que foram perceptíveis no trabalho matemático apresentado durante as atividades realizadas.

Palavras-chave: Derivadas; Ensino de cálculo; Integrais; Pensamento matemático avançado; Sequência fedathi.

\begin{abstract}
The objective of this article is to present a research focused on the teaching of Calculus, motivated by the difficulties shown by the students, especially in the Derivatives and Integrals contents. Therefore, it seeks to understand whether the use of the Fedathi Sequence (FS) teaching methodology by teachers can develop aspects of Advanced Mathematical Thinking (AMT) in the construction of students reasoning. The methodology took place with an initial literature review followed by a case study with subjects from a study group at the State University Vale do Acaraú, and for analysis of the results, the categories of the AMT Cognitive Theory, listed in the research development, were observed. The results showed that the change in teaching posture raised other students demands that were noticeable in the mathematical work presented during the activities performed.
\end{abstract}

Keywords: Derivatives; Calculus teaching; Integrals; Advanced mathematical thinking; Fedathi sequence.

\title{
Resumen
}

El objetivo de este artículo es presentar una investigación centrada en la enseñanza del Cálculo, motivada por las dificultades mostradas por los estudiantes, especialmente en los contenidos de Derivados e Integrales. Por lo tanto, busca comprender si el uso de la metodología de enseñanza de la Secuencia de Fedathi (SF) por parte de los maestros puede desarrollar aspectos del Pensamiento Matemático Avanzado (PMA) en la construcción del razonamiento por parte de los estudiantes. La metodología se realizó con una revisión inicial de la literatura seguida de un estudio de caso con los estudiantes de un grupo de estudio de la Universidad Estatal Vale do Acaraú como sujetos y para analizar los resultados, se observaron las categorías de Teoría Cognitiva de PMA enumeradas en el desarrollo de la investigación. Los resultados mostraron que el cambio en la postura de enseñanza planteó otras demandas de los estudiantes que se notaron en el trabajo matemático presentado durante las actividades realizadas.

Palabras clave: Derivados; Enseñanza de cálculo; Integrales; Pensamiento matemático avanzado; Secuencia de fedathi. 


\section{Introdução}

No decorrer da formação acadêmica dos estudantes situados em cursos da área de exatas, alguns discentes apresentam dificuldade em aprender assuntos vistos na disciplina de Cálculo Diferencial e Integral (CDI) e alguns fatores contribuem para isso. Inicialmente, a formação dos estudantes no ensino básico, que mesmo tendo uma boa noção matemática, "não dominam conteúdos de Álgebra e Geometria do ensino fundamental, bem como os relativos a Trigonometria e Geometria Espacial, do ensino médio" (Cury \& Cassol, 2004). Desta forma não estão preparados para trabalhar com ferramentas e conceitos do CDI, outro fator é o próprio descaso dos discentes com o hábito de estudar, muitas vezes por achar que não haverá tantas dificuldades em um curso da área com que mais se identifica, além disso, a postura tradicional do docente é "outro fator que se supõe interferir no rendimento dos alunos é a maneira de o professor repassar os conhecimentos" (Barbosa \& Neto, 1995).

Com isso foi motivada uma investigação sobre o conteúdo matemático e a forma como é ministrado pelo docente e, também, assimilado por parte dos discentes. Diante disso, o lócus da pesquisa aconteceu no Grupo de Estudos de Cálculo Diferencial e Integral, do Curso de Licenciatura em Matemática da Universidade Estadual Vale do Acaraú (UVA) no semestre 2019.1, com aulas ministradas por um docente efetivo do curso, de onde foram extraídos os sujeitos: os alunos inscritos em tal atividade de extensão.

Diante disso, buscou-se investigar se a aplicação, por parte do professor da metodologia de ensino Sequência Fedathi, com os alunos matriculados no Grupo de Estudos desenvolveram aspectos cognitivos específicos sobre o Pensamento Matemático Avançado, que serviria de auxílio na análise de resultados para entender analisando a existência de uma aprendizagem significativa, buscando evidenciar a eficácia dessa metodologia.

Esta pesquisa foi desenvolvida a partir das lacunas observadas pelos autores na acentuada dificuldade apresentada por partes dos estudantes na apreensão dos conceitos relacionados ao Cálculo Diferencial e Integral. O objetivo deste artigo é apresentar uma pesquisa voltada para o ensino de Cálculo, motivada pelas dificuldades mostradas pelos estudantes especialmente nos conteúdos de Derivadas e Integrais.

O referencial teórico contempla ideias desenvolvidas por (Menezes, 2018; Borges Neto, 2018;) na perspectiva da Sequência Fedathi como metodologia de ensino, especialmente, os conceitos de Plateau, Tomada de Posição, Maturação, Solução e Prova que irão auxiliar o professor com relação à maneira com que deverá conduzir suas aulas, buscando desenvolver o protagonismo e a construção do processo de aprendizagem por parte dos 
discentes. Fundamentamos essa pesquisa também na perspectiva do Pensamento Matemático Avançado (Tall, 1991; Vinner, 1991) especialmente nos construtos de Conceito Imagem e Conceito Definição, que serão úteis na análise dos resultados obtidos com relação ao desenvolvimento de traços cognitivos que auxiliarão o estudante na apreensão dos conceitos relacionados ao conteúdo de Derivadas.

Uma pesquisa é realizada para trazer novos saberes à sociedade como preconiza Pereira et al. (2018). No presente estudo procura-se realizar uma pesquisa educacional voltada para o aprendizado de CDI. Como metodologia contemplou-se uma abordagem de cunho qualitativo, na qual se optou em seguir como método científico os aportes teóricos da SF, diante disso houve como sujeitos a serem investigados os discentes do curso de licenciatura em matemática da UVA inscritos no grupo de estudo relativamente ao CDI, na qual para obter e analisar os dados obtidos por meio da pesquisa teve-se uma aplicação de um questionário para todos os participantes do projeto para mensurar a contribuição que teve em relação à caracterização da postura do professor utilizando a SF nas aulas e a aprendizagem dos discentes no tocante ao conteúdo da disciplina de CDI e o desenvolvimento das características referente ao PMA.

Desta forma será exposta posteriormente uma explicação detalhada da maneira de como tradicionalmente é ministrado o ensino de CDI mediante a postura dos professores, logo após sobre nosso referencial teórico, isto é, sobre a metodologia de ensino da SF usada na pesquisa e também a respeito do PMA, por fim todos os resultados encontrados durante o decorrer da pesquisa será exposto de maneira bem detalhada para contribuir significativamente para a educação matemática e o ensino do CDI.

\section{Ensino de Cálculo Diferencial e Integral}

Observa-se que estudantes da educação básica, mais especificamente do ensino médio a qual se destacam na disciplina de matemática tirando notas excelentes tendem a buscar um curso de ensino superior na área de exatas por terem tido mais facilidade, sendo o curso de matemática (licenciatura ou bacharelado) uma das principais opções devido ao seu desempenho em tal disciplina nos níveis básicos. De acordo com as experiências dos autores no curso de Matemática é perceptível que são transportadas para a Universidade uma falsa esperança de que não encontrarão dificuldades inerentes para sua aprendizagem no curso. Silva (2008) descreve que os alunos quando chegam ao nível superior acabam transportando consigo expectativas em relação a formação básica pelo fato de terem excelentes notas 
durante o Ensino Médio. Entretanto quando chegam ao nível superior acabam por se depararem com uma realidade totalmente diferente da esperada quanto ao nível dos conteúdos estudados, trabalhando com abstrações, conjecturas, teoremas e assim tratando problemas em um nível mais complexo, nas disciplinas de CDI isso não é diferente, tornando-se uma situação muito comum nas universidades, tendo como consequência reprovações, desistências e uma quebra de expectativa quanto ao curso de escolha. Tradicionalmente alguns dos professores que ensinam as disciplinas de CDI nos cursos das áreas de exatas tendem a seguir o mesmo padrão de ensino, adotando uma postura tradicional, fazendo assim com que o ensino ocorra de uma forma mecânica. Segundo Baldino (1998) no Ensino Tradicional Vigente (ETV) o professor ensina mostrando e o aluno aprende vendo. Com isso os estudantes apresentam dificuldade em desenvolver o conhecimento, bem como o senso investigativo, algo que é de extrema importância nos cursos de Matemática onde se trabalha bastante com processos abstratos que necessitam mais do "pensar" que do "fazer conta".

Em alguns cursos de Exatas, em especial no curso de Matemática os discentes não possuem uma preparação necessária, isto é, um "pré-cálculo" básico para as disciplinas de Cálculo Diferencial e Integral, e assim ao se depararem com os conteúdos que trazem consigo questões globais envolvendo todos os assuntos, onde a base de conteúdo teria que ser sólida. Contudo, a postura de como os docentes ministram suas aulas podem ser um fator para que os estudantes possam aprender, visto que a metodologia de ensino da SF torna viável a aprendizagem significativa de matemática dos discentes na vida acadêmica, possibilitando o melhor entendimento das linguagens complexas dos livros e ainda passando mais segurança aos estudantes durante seus desenvolvimentos cognitivos.

\section{Sequência Fedathi (SF)}

Algo de moderno para a educação matemática foi criada na década de 1980. Menezes (2018) afirma que através das experiencias do Prof. Dr. Hermínio Borges Neto na Université Paris Dideton na França, havia o intuito de descobrir como é a atitude do professor para o desenvolvimento do conhecimento matemático, assim começou o surgimento da conhecida hoje como Sequência Fedathi. Deste os docentes das instituições de redes privada como as demais do sistema público podem utilizar esse método nas suas aulas, pelo fato de estar voltada para o modo de como os profissionais da educação ensina no ambiente escolar.

Atualmente alguns professores utilizam o ensino tradicional durante a apresentação dos conteúdos obrigatórios das disciplinas letivas no ensino superior ou na educação básica. 
Essa estrutura de ensino possibilita uma desconexão entre docente e discente, pelo fato de apenas o professor discursa o assunto e os alunos apenas ouvir ocasionado desta maneira complicações na aprendizagem. Nesse contexto, (Sousa, et al.,2013) explica que:

O ensino tradicional, além de sobrecarregar o professor antes, durante e depois das aulas, subtrai do aluno a possibilidade de participar e contribuir com o desenvolvimento de sua aprendizagem e dos outros alunos, pois, ao ficar na condição de "mero espectador" deixará de expor suas dúvidas, reflexões e hipóteses, as quais poderiam ser de grande valia para todo grupo, no decorrer do assunto estudado.

Assim, tratando em transformar os estudantes em seres compromissados com a construção do seu próprio conhecimento, tendo como intercessor o educador encontre-se a SF, conforme afirma Cardoso (2015) "A SF é empregada na busca de desenvolver no professor uma postura mediadora que estimule uma participação mais ativa do aluno em seu processo de construção do conhecimento".

$\mathrm{Na}$ SF é exposto um problema desafiador aos estudantes, e ela serve para nortear $\mathbf{o}$ trabalho docente durante a aplicação e como agir em algumas ocasiões no decorrer da aplicação. Possibilitando aos discentes serem os descobridores e o docente o condutor, assim isto "ocorre de acordo com as etapas a serem seguidas numa sessão didática: tomada de posição, maturação, solução e prova" (Menezes,2018). Sendo que antes desse ciclo há o plateau de extrema relevância.

\section{Plateau}

Momento do plateau, segundo Bezerra (2017) refere-se ao "conjunto de conhecimentos compreendidos pelos alunos e dominados pelo professor", ou seja, é necessário primeiramente que o docente tenha o entendimento do conteúdo a ser abordado por meio da aplicação, e além disso saber o nível de conhecimento trazidos pelos estudantes para o desenvolvimento e compreensão do novo.

Esse momento tem uma grande importância no desenvolvimento da execução na SF, pois vai investigar primeiro o nível que os estudantes possuem a fim de haver a possibilidade de todos os integrantes da turma resolver o problema proposto pelo docente. Com o intuito de aplicar atividade que seja viável tanto para os estudantes com alguma dificuldade inerente como os demais, isto é, que haja a participação de ambos. 
De acordo com Fontenele (2013) "o plateau necessário para o acompanhamento dos novos conteúdos a serem abordados, conforme preconiza a sequência fedathi”, ou seja, é necessário que os estudantes tenham o pré-requisito necessário para aquisição dos novos conceitos a serem aprendidos no decorrer do seguimento da aplicação, e assim desenvolve o novo conhecimento.

\section{Tomada de Posição}

Na tomada de posição é contemplado a apresentação do problema generalizável em caráter desafiador aos estudantes, mas que esteja de acordo com o nível de conhecimento de cada indivíduo participante no processo. Esse problema proposto pelo professor necessita "ter relação com o conhecimento a ser ensinado" (ANDRADE et al.,2019).

Devido isso é necessário haver uma análise da turma para o professor escolher o problema a ser aplicado na sala de aula de acordo com o nível de conhecimento dos discentes para eles não desistirem, ou seja, há a necessidade de um planejamento cauteloso. De acordo com Sousa (2010), “[...] é importante que o problema tenha como um dos meios de resolução a aplicação do saber em jogo", isto é, que não esteja impossível de ser resolvido do ponto de vista da bagagem de conhecimento adquirindo na vida acadêmica ou social dos estudantes, e também que haja obrigatoriamente mais de um caminho possível de se chegar ao resultado proposta pelo óbice.

Sendo que nesta etapa o professor poderá expor essa situação problema e aplicá-la de diversas maneiras como, por exemplo, de um jogo pedagógico, de uma pergunta, de manipulação de materiais concretos, de experimentações de algum software, podendo os estudantes trabalhar na resolução do problema de maneira individual ou coletiva. Na tomada de posição o professor deverá esclarecer possíveis dúvidas que possam surgir frente ao problema proposto e, ademais está incentivado os discentes no trabalho individual ou coletivo.

\section{Maturação}

Etapa destinada para construção do raciocínio dos estudantes, pois pela leitura e interpretação do problema proposto na tomada de posição, na qual eles devem retirar os dados contidos em busca de traçar os possíveis caminhos que possam destina-los na resolução da 
atividade. Sendo no surgimento de algumas dúvidas em relação ao desafio feito, o professor poderá auxiliar da maneira mais estimulante para o desenvolvimento da resolução, mas que não entregue feita a resposta ao discente e nem " sobre alguma passagem para solucionar a questão proposta, poderá utilizar-se de contraexemplos e aplicações”(Menezes, 2018)

No decorrer da aplicação do problema o docente deve estar atento a todas as possíveis reações feitas pelos estudantes, tais como: ao comportamento, estresse, medo, atitude e as estratégias criadas para solucionar o desafio estabelecido no início da tomada de posição. Essas observações podem auxiliar o professor em estabelecer meios de mediar as informações frente ao discente além de estimula-los a prosseguir na resolução sem haver desistência por parte de alguns que se consideram incapazes de solucionar a atividade.

\section{Solução}

Essa é a fase é ocasionada para os estudantes apresentarem as resoluções encontradas durante o processo da maturação, podendo ser feita por meio de linguagem matemática, escrita, desenho ou até mesmo transversamente pela escrita. Neste momento ocorre a troca de ideias a respeito das resoluções entre os discentes e o professor, caso não haja estudantes proposto a apresentarem a resolução na lousa, o aplicador deverá estimula-los a participarem. Segundo o autor Menezes (2018) "as soluções que não se aproximaram da resposta esperada deverão ser refutadas com apresentação de contraexemplos", ou seja, no decorrer da exposição das respostas o docente fará com que os estudantes descubram os erros cometidos durante o processo ocorrido, e assim desenvolver essa visão.

Contudo é necessário que haja um tempo para os próprios estudantes desenvolverem uma avaliação à cerca de suas realizações e resposta por meio de ensaios, e assim encontre os erros e avaliarem seus modelos criados, pois este é o momento em que vão exercer autonomia no processo ensino-aprendizagem. O professor é como mediador que junto aos estudantes discutirá as resoluções encontradas, a fim de que possa concluir qual delas está mais adequada para resolver o problema proposto, sabendo que o professor deverá ainda está incentivado os estudantes para que erros cometidos acabem não surgindo mais diante deles.

\section{Prova}

Levando em considerações as fases anteriores ocorrida com êxodo, nesta o profissional ministrador do problema deverá fazer a formalização do conteúdo dando a solução oficial da atividade, visando assimilar os modelos feitos pelos estudantes com o oficial, mas sempre 
mantendo a atenção e motivando o grupo e ainda deve fazer a resolução em linguagem matemática e juntamente com as novas regras de conhecimento inerentes para resolução fornecidas pelos discentes. De acordo

A palavra "Prova", usada na Sequência Fedathi, possui a função de caracterizar uma fase em que o professor explicará o problema exposto em linguagem formal, relacionando com as soluções dos estudantes e os caminhos percorridos, pois nem sempre será provada uma afirmação, ou seja, o referencial para dosar este momento é a Tomada de Posição e, claro, o objetivo do docente para determinada sessão didática (Ibid, 2018).

Sendo nesta fase final é que o conhecimento deverá sem entendido pelos estudantes e desta maneira essa noção poderá ser usada futuramente em outras resoluções e construção de outros esquemas adiante. Isto é, o conhecimento adquirindo durante o processo da aplicação do desafio pelo professor pode ser utilizado futuramente em outros conteúdos proposto pelo docente.

\section{Pensamento Matemático Avançado}

Tall (1995) realiza, desde a perspectiva cognitivista, uma sistematização do pensamento matemático através de três componentes da atividade humana: a percepção como entrada, o pensamento como processo interno e a ação como saída. Desse modo vem a considerar parte do pensamento matemático, a interação com os objetos do mundo externo e ações exercidas sobre estes, o Pensamento Matemático Avançado vem a surgir em fases seguintes do Pensamento Matemático Elementar, onde tais interações passam a se tornar mais complexas e consequentemente o estudante passa ter ações de cunho avançado para poder manipular determinado problema.

Segundo Tall (1991) a composição do Pensamento Matemático Avançado se dá em todo um processo que parte da busca por entender um problema, passando pelo ato de pensar nesse problema, levantando conjecturas e em estágios posteriores na formulação de Teoremas. Nesse contexto PMA e Sequência Fedathi, possuem convergências importantes para a construção de tal pesquisa, já que durante as fases da Sequência Fedathi as intervenções do professor possibilitam com que possam aparecer em melhor qualidade esses processos, assim, tratando os problemas em um nível de complexidade onde os estudantes possam participar diretamente da construção do conhecimento. Na perspectiva dessa teoria cognitiva, são evocados dois importantes construtos baseados no trabalho de Vinner (1991), a serem tratados, são eles o Conceito Imagem e Conceito Definição. Este autor preocupa-se 
essencialmente com a construção de conceitos matemáticos mais abstratos, que é o enfoque de nossa pesquisa.

Conceito Imagem trata-se daquilo que o estudante consegue produzir em sua mente sobre determinado conteúdo, como o próprio nome já diz, há uma formação de uma determinada imagem sobre um dado conceito, ou ainda a produção de ideias que se relacionem diretamente com um determinado conceito, trata-se de uma coleção de sensações sobre este. É um processo construído ao longo de toda a formação do estudante, onde este se depara com diferentes experiências e ao ser confrontado com novos estímulos vai agregando mais conhecimento, havendo a possibilidade de mudar sua interpretação acerca de um conceito. É necessário destacar que no Conceito Imagem não há presença de verbalização ou transcrição, trata-se apenas de associações mentais ou coleções de impressões ou experiências relacionadas a tal conceito.

[..]Quando você ouve a palavra "função" por outro lado, você pode lembrar-se da expressão " $\mathrm{y}=\mathrm{f}(\mathrm{x})$ ", você pode visualizar o gráfico de uma função, você pode pensar sobre funções específicas como $y=x^{2}$ ou $y=\operatorname{sen}(x), y=\ln x$ etc. Do que nós dissemos, está claro que só é possível falar de imagem conceitual em relação a um sujeito específico. Além disso, o mesmo indivíduo poderia reagir de modo diferente a certo termo (nome do conceito) em situações diferentes (Vinner, 1991).

Assim, o Conceito Imagem sobre determinado objeto não é único, cada indivíduo irá fazer as associações mais convenientes para a situação a se utilizar aquela imagem sobre o conceito, por isso, pode ocorrer que essa imagem não esteja associada de maneira correta com o conceito, podendo impactar na construção das definições.

Com relação ao Conceito Definição temos a presença de verbalização bem como transcrição, como o próprio nome sugere, identificamos a definição de um determinado conceito. Vinner (1983) afirma que se trata de uma definição verbal que explica determinado conceito de uma forma precisa. É importante ressaltar que por se tratar de uma definição, poderão haver diferentes interpretações sobre um mesmo conceito, de modo que estas interpretações serão denominadas de Conceito Definição Pessoal, enquanto as definições precisas serão tratadas como Conceito Definição Formal.

Cada estudante irá construir um esquema próprio que o auxilie no entendimento de tal conceito, partindo para um Conceito Definição Pessoal, que se trata daquela definição construída por um estudante sobre determinada definição formal, podemos entender então o Conceito Definição Pessoal como sendo a interpretação que um estudante tem sobre 
determinada definição formal e ainda sobre determinada imagem de um conceito. Deve-se perceber que nem sempre essa definição pessoal irá estar de acordo com a definição formal, ou seja, há possibilidade de uma construção de uma definição pessoal de forma errônea, não retratando o que a definição formal traz.

Segundo Tall e Vinner (1981) a definição pode ser aprendida através de mais de uma forma, seja de forma mecânica ou mais significativa relacionando ao conceito como um todo, podendo ainda ser uma reconstrução pessoal de modo que o estudante poderá variá-la de acordo com a maneira que seja feita a apreensão do conceito. O modo de apreensão de uma definição é de grande importância na aprendizagem do estudante, pois estará condicionado com a fixação ou não daquele determinado conceito em sua mente, já que, se o mesmo aprende de uma forma mecanizada tenderá a apenas reproduzir o que lhe foi passado, enquanto se este tem a possibilidade de construir o próprio conceito poderá variá-lo de acordo com a situação em que se apresente.

É importante entender que se o aluno apenas verbalizar uma Definição Conceitual Formal não podemos dizer que aquele conceito foi entendido por ele. Para que haja traços de construção de conhecimento o estudante deve possuir construções de Conceitos Imagens, ou seja, projetar em sua mente esquemas, experiências ou propriamente imagens sobre determinado conceito, como também, apresentar Conceito Definição Pessoal que esteja de acordo com a definição formal. Para Vinner (1991) conhecer a definição não é garantia de compreensão, é necessário que, conheça a imagem.

Por exemplo, os conceitos de casa ou laranja não foram adquiridos por meio de uma definição e, no entanto, temos conceitos imagem bastante claros deste tipo de objetos. Alguns conceitos podem, no entanto, ser introduzidos por meio da definição, ajudando esta a formar o conceito imagem. Por exemplo, se pretendermos explicar a uma criança o que é uma floresta podemos dizer que se trata de "uma zona onde podemos encontrar muitas árvores juntas", podendo a criança formar um conceito imagem a partir desta definição. No entanto, a partir do momento em que o conceito imagem se forme, a definição pode permanecer inativa ou mesmo ser esquecida quando manejamos esse conceito (Domingos, 2006).

Logo, quando se falar em determinado conteúdo para o estudante, este não necessariamente irá evocar a definição em sua mente, entretanto com certeza irá formar-se a imagem referente a um conceito, e com a formação da imagem o mesmo poderá reconstruir o conceito para si.

Vinner (1983) propõe um modelo referente a construção do conhecimento a partir de duas células (não células biológicas) referentes ao conceito, umas destas guardará definições 
enquanto outra deve guardar imagens. Uma das duas pode estar vazia ou até mesmo as duas, a célula da imagem, por exemplo, estará vazia quando forem apenas memorizados os conceitos sobre determinados objetos, entretanto não fora assimilada nenhuma imagem ou nenhum significado importante sobre este, o autor ressalta a importância de uma interação entre estas duas células para que assim o conhecimento se dê de uma maneira mais significativa.

\section{Aplicação e Análise de Resultados}

A pesquisa desenvolveu-se a partir de um pré-teste contendo 4 questões que fora aplicado aos estudantes, sendo que sete dos oito alunos que participaram já haviam cursado ou estavam cursando disciplinas de Cálculo naquele momento. Esse teste era referente ao conteúdo de Integrais que ainda não havia sido ministrado no Grupo de Estudos, ou seja, os alunos estavam munidos das ideias do conteúdo de Derivadas, bem como do que já se tinha estudado na disciplina de Cálculo II do curso, onde são apresentadas as Integrais. Assim, buscou-se identificar o nível em que estavam os conhecimentos prévios dos estudantes em relação a Derivadas, como também o que já haviam estudado no curso de Matemática, o que é de grande importância no Plateau na Sequência Fedathi, e a partir disso fora acompanhado o desenvolvimento dos estudantes participantes durante a referida atividade do grupo de estudos, mediante a aplicação da Sequência Fedathi por parte do professor durante a aplicação das sessões didáticas.

O grupo de estudos de Cálculo Diferencial e Integral ocorreu em 2019.1, com 12 sessões didáticas, participando em média 15 alunos do curso de Licenciatura em Matemática e versaram sobre as temáticas de Derivadas - conceitos e aplicações - e Integrais - definições, técnicas de integração e aplicações nas Séries de Taylor e Mac'Laurin.

Para tal análise buscou-se identificar aspectos da teoria do PMA, principalmente se havia a presença de Conceito Definição e Conceito Imagem, pois a partir da interação entre ambos se torna possível identificar a aprendizagem. Já que, para Vinner (1991) o que garante o entendimento do conceito é a presença de Conceito Imagem. Diante disso, para definir onde estavam presentes esses construtos do Pensamento Matemático Avançado, fora feita a resolução dos exercícios por parte dos autores, e ao identificar a estratégia adotada para se obter êxito na resolução da questão, se descreveu determinada ideia em Conceito Definição ou Conceito Imagem, por exemplo, se o estudante recorre a uma Primitiva Imediata, este irá estar se utilizando de um Conceito Imagem, pois ao se deparar com a função que está sendo integrada, irá associá-la rapidamente a sua primitiva ou antiderivada. 
A partir dessas ideias foi realizada a análise nas resoluções dos exercícios propostos pelo professor, que contemplou as análises da técnica de integração adotada pelo estudante na resolução de determinada Integral, da maneira de manipular uma determinada função para facilitar os cálculos no exercício, do resultado final obtido e também o uso de outros conteúdos da Matemática, como, Geometria Analítica, Trigonometria e a própria Álgebra. É importante ressaltar que numa análise de questionário onde busca-se entender aspectos cognitivos, não bastou apenas olhar as questões e constatar o que estava certo e o que estava errado, fora também feita uma minuciosa resolução do questionário por parte dos autores, com a finalidade de entender todo o desenvolvimento cognitivo necessário para resolver a questão e assim identificar cada ideia utilizada como um conceito definição ou conceito imagem. De acordo com esses critérios, foi identificada a presença de Conceito Definição, tanto pessoal quanto formal em $41 \%$ dos casos, porém isso não refletiu no índice de acertos, evidenciando que esse construto, de maneira isolada, não é suficiente para caracterizar aprendizagem, tanto é que o índice de acertos esteve em torno de $21 \%$ ficando bem próximo do percentual de casos onde se pôde identificar Conceito Imagem, que esteve com aproximados $19 \%$. Veja as Figuras 1 e 2:

Figura 1: Percentual da presença e ausência de Conceito Definição e Conceito Imagem no questionário pré-teste.

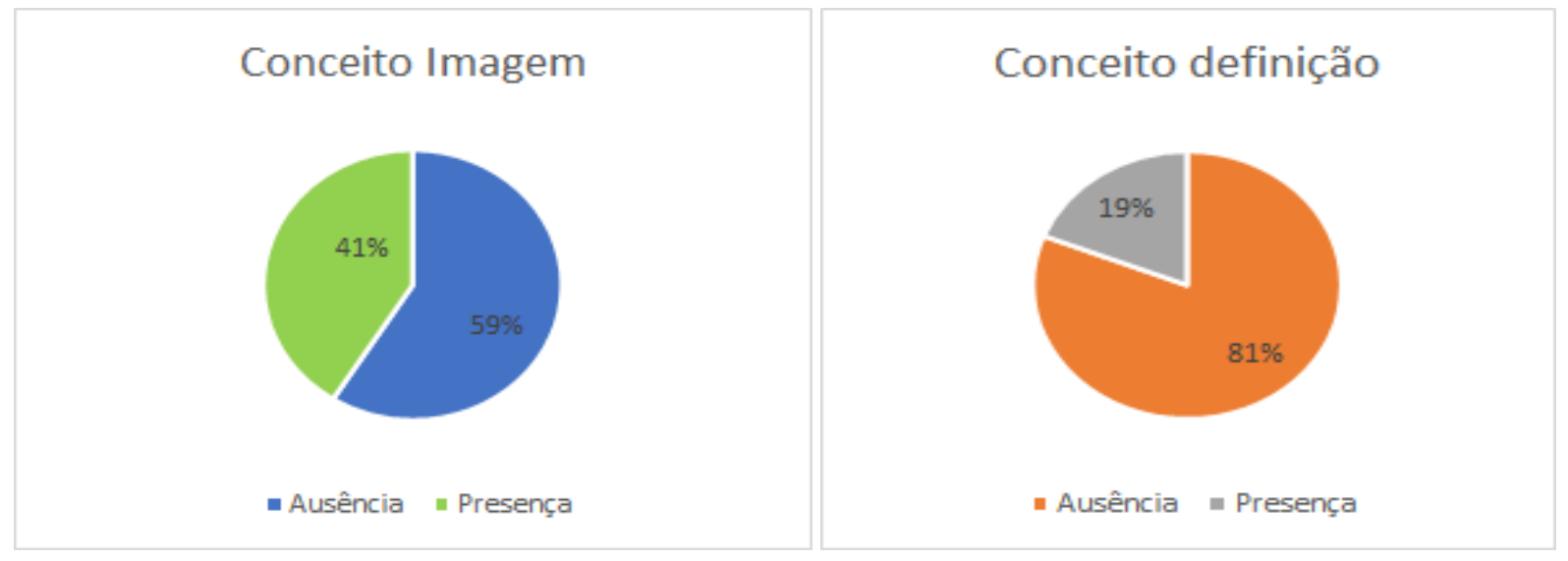

Fonte: Autoria Própria. 
Figura 2: Percentual de erros e acertos no questionário pré-teste.

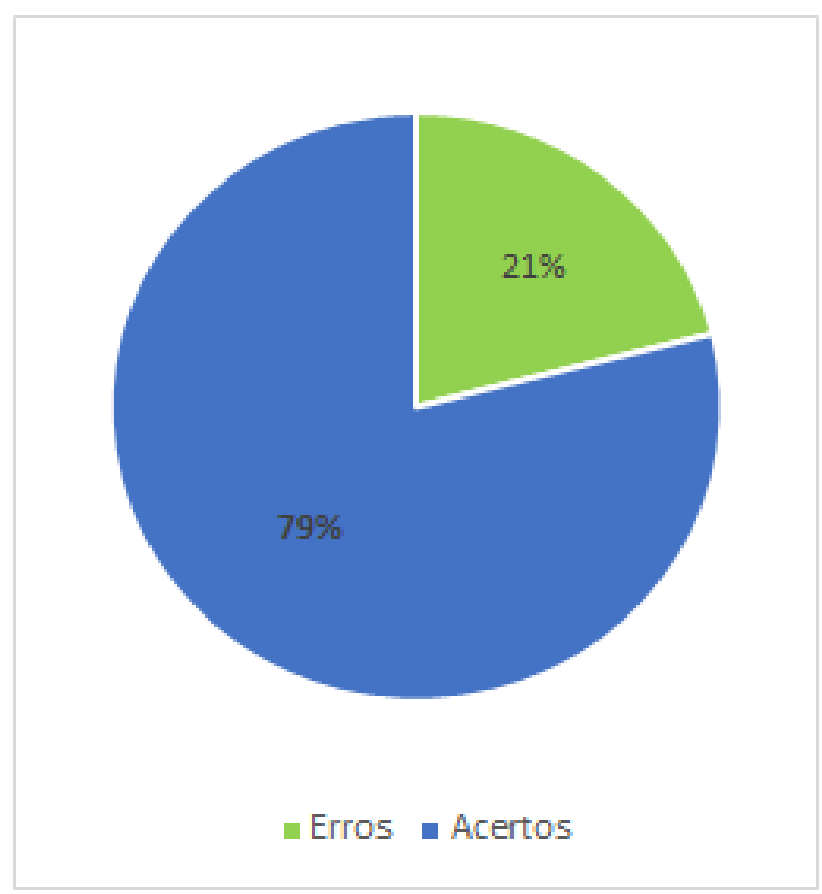

Fonte: Autoria Própria.

De acordo com os gráficos apresentados nas Figuras 1 e 2 é possível perceber inicialmente que os estudantes apresentavam baixa incidência de Conceitos Definição e Imagem, e isso foi reflexo no resultado final dos exercícios. De maneira mais direta, é perceptível uma relação entre o número de acertos e a aparição de Conceito Imagem, onde de acordo com Vinner (1991) "adquirir um conceito significa formar uma imagem conceitual para ele. Saber a definição conceitual de cor não garante o entendimento do conceito. Entender, como acreditamos, significa ter um Conceito Imagem. Certos significados devem ser associados com as palavras".

Na Figura 3 observa-se o desenvolvimento de um raciocínio, onde, consequentemente terá a aparição de Conceito Definição e Conceito Imagem. Nesta questão o aluno desenvolveu todo o seu raciocínio de maneira correta, se utilizando das ideias de método de integração, primitiva imediata, e Teorema Fundamental do Cálculo, assim o mesmo obteve êxito na resolução desse exercício. 
Figura 3: Exercício de Integração pelo método de mudança de variável.

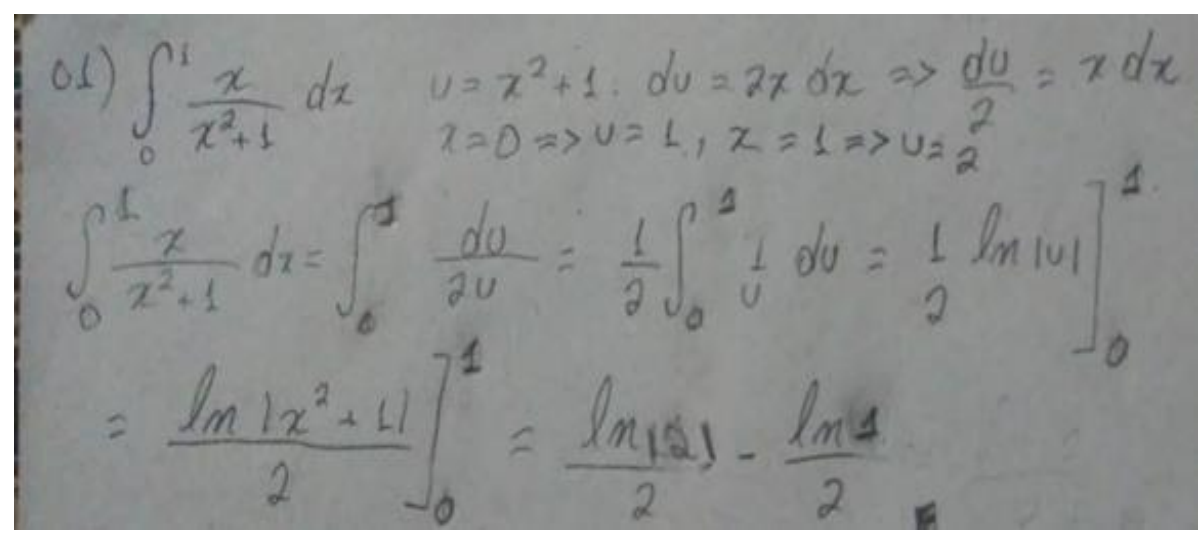

Fonte: protocolos da pesquisa.

Também é importante destacar que as dificuldades dos estudantes na resolução de exercícios referente ao conteúdo de Integrais não se dão somente na técnica de integração escolhida, existe também uma dificuldade na forma de abordar o problema, limitando-se apenas a integrar, excluindo assim a possibilidade de uma manipulação na função que está sendo integrada para que a ideia escolhida na resolução tenha uma maior clareza. Ou seja, em uma parte dos casos, as dificuldades são observadas nos conteúdos básicos estudados, como Trigonometria por exemplo.

Veja a Figura 4, onde um dos alunos buscou usar o método de integração por substituição, porém o mesmo não se atentou a Trigonometria, e excluiu a possibilidade de manipular a função no integrando, o que seria a estratégia ideal para essa questão. Assim, o aluno não obteve êxito, tanto é que não conseguiu dar continuidade em seu raciocínio.

Figura 4: Exercício de integração com uma função trigonométrica no integrando

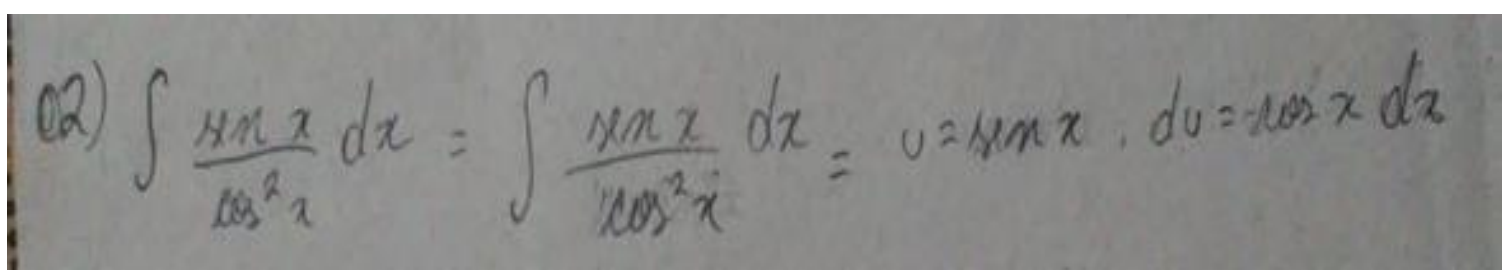

Fonte: protocolos da pesquisa.

Para transpor essas dificuldades, foi implementada por parte do professor em suas sessões didáticas a metodologia de ensino Sequência Fedathi, propiciando assim com que os alunos se tornassem protagonistas na construção do próprio conhecimento, não apenas sendo receptores, mas sim participando ativamente da construção do conhecimento. Desse modo 
foram propostos exercícios de cunho "generalizável" para eles conforme definição da etapa "Tomada de Posição", a fim de que pudessem entender tanto as técnicas de integração, quanto pudessem desenvolver esse senso investigativo, com o qual iriam traçar estratégias mais eficientes na resolução dos exercícios. Outro ponto importante foi que, com a aplicação deste pré-teste o professor pôde adequar suas sessões didáticas com o nível de conhecimentos prévios da turma, traçando o correto plateau da turma e possibilitando um melhor aproveitamento das aulas por parte dos discentes.

Foi papel dos autores acompanhar o desenvolvimento das atividades do Grupo de Estudos, assim, buscando identificar a evolução dos alunos a partir da aplicação da metodologia SF, tal acompanhamento foi feito durante as resoluções das atividades propostas pelo professor, e pôde-se concluir que no desenvolvimento das sessões didáticas os mesmos apresentaram uma satisfatória evolução nas soluções apresentadas nos exercícios, reconhecendo o que deveriam aplicar numa determinada resolução de um problema, bem como puderam ressignificar seu aprendizado quanto ao conteúdo de Derivadas e assim entender sua importância para fazer uma boa disciplina de Cálculo II.

\section{Considerações Finais}

Considerando o que foi exposto no decorrer desta pesquisa, a partir da aplicação da metodologia de ensino Sequência Fedathi nas sessões didáticas do grupo de estudos de Cálculo Diferencial e Integral observou-se que os estudantes desenvolveram traços do PMA, tanto Conceito Definição quanto Conceito Imagem, pôde-se perceber isso através da observação por parte dos autores da participação dos estudantes durante as aulas, onde eram motivados pelo professor a estarem inseridos de maneira ativa na construção do seu conhecimento mesmo de forma incipiente nas primeiras aulas, a evolução foi se dando gradualmente no prosseguimento das atividades, demonstrando, assim, os Conceitos Definição e Imagem nos estudantes.

Pôde-se perceber, através da observação das sessões didáticas por parte dos autores que a metodologia de ensino apresentou vantagens, mas limitações perante ao acordo didático já estabelecido pelos professores da instituição, pela falta de homogeneidade neste quesito. Quanto ao universo dos sujeitos de estudo que se limitou apenas aos que estavam matriculados no grupo de estudos, foi uma reduzida estratificação, mas pretende-se realizar estudos investigativos com a SF, podendo assim ser aplicada nas mais diversas sessões didáticas dos cursos de graduação, bem como na educação básica. 
Dessa forma, a partir da aplicação da SF no grupo de estudos houve uma contribuição para a aprendizagem dos discentes, propiciando assim uma melhor apreensão dos conceitos referentes às disciplinas de cálculo Diferencial e Integral. Com isso foi possível atingir o objetivo desse trabalho, que representa uma contribuição literária para que os professores universitários utilizem a SF em suas aulas nos cursos de graduação da Universidade Estadual Vale do Acaraú (UVA) a fim de progredir para uma aprendizagem mais significativa dos estudantes e consequentemente aumentar o nível de aprovações na disciplina de CDI.

Tem-se como pretensões futuras expandir e apresentar os resultados no âmbito do curso de licenciatura em matemática da UVA, além de prosseguir os estudos sobre o CDI para uma quantidade mais significativa de sujeitos com o intuito de ter um resultado mais fidedigno sobre a aplicações das sessões didática na SF e o desenvolvimento dos trações do PMA nos discentes. Por fim, espera-se que os resultados encontrados nessa pesquisa tenham contribuído para o progresso da educação matemática no ensino do CDI em âmbito nacional.

\section{Referências}

Andrade, WE et al. (2019). A metodologia sequência fedathi no processo de formação docente, de ensino e de aprendizagem de matemática: uma revisão integrativa. Brazilian Jornal of Development, 5(12), 29858-29869. doi:https://doi.org/10.34117/bjdv5n12-126

Baldino, RR. (1998). Desenvolvimento de Essências de Cálculo Infinitesimal. Rio de Janeiro: MEM/USU.

Barbosa, GO \& Borges Neto, H. (1994). Raciocínio lógico formal e aprendizagem em cálculo diferencial e integral: o caso da Universidade Federal do Ceará. Dissertação -Universidade Federal do Ceará (Faculdade de Educação) Departamento de Estudos Especializados, Fortaleza.

Bezerra, AMA. (2018). O Plateau como elemento de reflexão e melhoria das práticas escolares. Curitiba: Crv.

Cardoso, RPL. (2015). MASF: Modelo de Referência para aplicação da Sequência Fedathi na formação profissional e na produção de conteúdo. Tese (Doutorado) -Universidade Federal do Ceará (Faculdade de Educação) Programa de Pós-Graduação em Educação 
Brasileira, Fortaleza.

Cury, HN \& Cassol, M. (2004). Análise de erro em Cálculo: uma pesquisa para embasar mudanças. Acta Scientiae, 6(1), 27-36. Retirado de http://www.periodicos.ulbra.br/index.php/acta/article/view/128/116

Domingos, A. (2006). Teorias cognitivas e aprendizagem de conceitos matemáticos avançados. In: Seminário de Investigação em Educação Matemática, 17, Actas, 17, 51-81. Retirado de https://www.researchgate.net/publication/267806630

Fontenele, FCF. (2013). A sequência fedathi no ensino da álgebra linear: o caso da noção de base de um espaço vetorial. Dissertação (Mestrado em Educação) - Faculdade de Educação, Universidade Federal do Ceará, Fortaleza.

Menezes, DB. (2018). O Ensino do Cálculo Diferencial e Integral na Perspectiva da Sequência Fedathi: Caracterização da Mediação de um Bom Professor. Tese (Doutorado) Programa de Pós-Graduação em Educação Brasileira. Universidade Federal do Ceará, Fortaleza.

Pereira, AS, Shitsuka, DM, Parreira, FJ \& Shitsuka, R. (2018). Metodologia da pesquisa científica. [e-book]. Santa Maria. Ed. UAB/NTE/UFSM. Disponível em: https://repositorio.ufsm.br/bitstream/handle/1/15824/Lic_Computacao_MetodologiaPesquisa-Cientifica.pdf? sequence $=1$.

Souza, MJA. (2010) Aplicações da Sequência Fedathi no ensino e aprendizagem da Geometria mediada por tecnologias digitais. Tese (Doutorado em Educação) - Faculdade de Educação, Universidade Federal do Ceará, Fortaleza.

Souza, FEE et al. (2013) Sequência Fedathi: uma proposta pedagógica para o ensino de ciências e matemática. Fortaleza: edições UFC.

Silva, BA. (2008) Contrato Didático. In: Sílvia Dias Alcântara Machado. (Org.). Educação Matemática: Uma (nova) introdução. $3^{\text {a }}$ ed. São Paulo: EDUC. 
Research, Society and Development, v. 9, n. 7, e435973869, 2020

(CC BY 4.0) | ISSN 2525-3409 | DOI: http://dx.doi.org/10.33448/rsd-v9i7.3869

Tall, D. (1995) Cognitive growth in elementary and advanced mathematical thinking.

Proceedings of 19th International Conference for the Psychology of Mathematics Education, 1, 61-75. Retirado de http://citeseerx.ist.psu.edu/viewdoc/download

Tall, D. (1991) The psychology of advanced mathematical thinking. In: Tall, David (Org.). Advanced Mathematical Thinking. (pp.3-21) Dordrecht: Kluwer Academic Publishers.

Tall, D \& Vinner, S. (1981) Concept image and concept definition in mathematics with particular reference to limits and continuity. Educational Studies in Mathematics. University of Warwick. 12 (7), 151-169. doi:10.1007/BF00305619

Vinner, S. (1983). Concept definition, concept image and the notion of function. International Journal of Education in Science and Technology, 14, 293-305.

https://doi.org/10.1080/0020739830140305

Vinner, S. (1991) The Role of Definitions in Teaching and Learning. In: Tall, David (Org.). Advanced Mathematical Thinking. (pp. 65-81) Dordrecht: Kluwer Academic Publishers.

\section{Porcentagem de contribuição de cada autor no manuscrito}

Karllinson Magno Ávila Teófilo - 34\%

Francisco Leonardo da Silva Lima $-34 \%$

Daniel Brandão Menezes - 32\% 